\title{
Regional variation in pesticide concentrations in plasma of delivering women residing in rural Indian Ocean coastal regions of South Africa $\uparrow$
}

\author{
Kalavati R. Channa, ${ }^{* a b}$ Halina B. Röllin, ${ }^{c d}$ Kerry S. Wilson, ${ }^{b}$ Therese H. Nøst, ${ }^{a e}$ Jon Ø. Odland, ${ }^{a}$ Inakshi Naik ${ }^{b}$ \\ and Torkjel M. Sandanger ${ }^{a e}$
}

Received 2nd April 2012, Accepted 18th September 2012

DOI: $10.1039 / \mathrm{c} 2 \mathrm{em} 30264 \mathrm{k}$

\begin{abstract}
Exposure to pesticides places pregnant women and the developing foetus at the highest risk. The objective of this study is to obtain an exposure assessment by investigating levels of pesticides in blood plasma of delivering women. We report on the concentrations of $\alpha, \beta, \gamma \mathrm{HCH}$, endosulfan, $\mathrm{HCB}$ and the pyrethroids: cis-permethrin, cyfluthrin, cypermethrin and deltamethrin found in the maternal blood plasma of delivering women $(n=241)$ in three coastal sites of KwaZulu Natal. $\gamma$-HCH and endosulfan 1 and 2 were the most dominant pesticides in all three sites. Significantly, higher levels of $\gamma-\mathrm{HCH}$ and endosulfan were found in site 3 (vicinity of Empangeni) compared to the other two sites $(p<0.05)$. The GM levels for $\gamma-\mathrm{HCH}$, endosulfan 1 and 2 were 956, 141 and $21 \mathrm{ng} \mathrm{g}^{-1}$ lipids in site 3, respectively. The pyrethroid pesticides, $\mathrm{HCB}, \alpha-\mathrm{HCH}$ and $\beta-\mathrm{HCH}$ were detected in less than $31 \%$ of the samples in all sites. $\gamma-\mathrm{HCH}$ correlated positively and strongly to both endosulfan 1 and $2(r>0.47)$, indicating a common source of exposure. The high levels of $\gamma-\mathrm{HCH}$ and endosulfan in maternal plasma samples in site 3 indicate the current and on-going exposure, which is of great concern for reproductive health and prenatal exposure.
\end{abstract}

\section{Introduction}

In general, many organochlorine pesticides are considered to be of persistent and toxic nature in the environment, able to bioaccumulate both in environment biota and in the living organisms, including humans, and able to travel long distances to

\footnotetext{
${ }^{a}$ Institute of Community Medicine, University of Tromsø, Tromsø, Norway ${ }^{b}$ National Health Laboratory Services, NIOH, 25 Hospital Street, Constitutional Hill, Braamfontein, PO Box 4788, Johannesburg, 2000, South Africa. E-mail: Kalavati.channa@nioh.nhls.ac.za; Fax: +27 11 712 6533; Tel: +27117126439

${ }^{c}$ Medical Research Council, Johannesburg, South Africa

${ }^{d}$ University of Pretoria, South Africa

${ }^{e}$ Norwegian Institute for Air Research (NILU), Fram Centre, Tromsø, Norway

$\dagger$ Part of this work was presented at the Environmental Health Conference 2011 - Resetting our Priorities, Salvador, Brazil, 6-9 February 2011.
}

redeposit in some instances far away from the actual source. Many of these compounds are banned or restricted for use in agriculture and other applications. Although there is evidence of reduced current exposure to pesticides of the general population in developed countries, exposure through dietary intake is still evident, possibly due to the persistence of these pesticides. ${ }^{\mathbf{1 , 2}}$

In contrast, in developing countries including South Africa, some of these compounds are still being used, both in the commercial and small scale agricultural sectors, despite concerns regarding their toxicity. There is evidence of illegal production, trade and stockpiling of banned pesticides in a number of developing countries. ${ }^{3,4}$

Among the pesticides of concern are not only agrichemicals such as hexachlorobenzene (HCB), $\alpha$-, $\beta-, \quad \gamma$-hexachlorocyclohexane $(\mathrm{HCH})$, endosulfans, and 1,1,1-trichloro-2,2di(4-chlorophenyl)ethane(pp-DDT), but also newer compounds including organophosphates, herbicides, carbamates and

\section{Environmental impact}

Exposure to pesticides places pregnant women and the developing foetus at the highest risk. The increasing agricultural development in South African rural regions has resulted in the increasing number of women working in farms and thus their exposure to pesticides. Furthermore, these substances are widely used at the household level for insect and pest control. The objective of this study is to obtain an exposure assessment by investigating levels of pesticides in blood plasma of delivering women. Concentrations of $\alpha, \beta, \gamma \mathrm{HCH}$, endosulfan, HCB and the pyrethroids: cis-permethrin, cyfluthrin, cypermethrin and deltamethrin were measured as an indicator of prenatal exposure in three South African coastal regions. 
pyrethroids. Due to increased public and regulatory attention during the 1970s and 1980s, many legacy pesticides were banned leading to the development and licensing of new pesticides with less persistence and toxicity.

For example, lindane $(99 \% \gamma-\mathrm{HCH})$ has been in use as a broad range insecticide for the past 50 years and its toxic and environmental hazards are well defined. $\mathrm{HCH}$ is one of the nine chemicals included in the Stockholm Convention list of persistent organic pollutants (POPs), but it is still used for control of head lice and scabies in some countries. Another organochlorine pesticide, endosulfan, is also widely used and is thought to be one of the world's most widespread pollutants. It is found in water, air, soil, snow and ice deposits, and in most remote areas of the world such as the Molopo Nature Reserve (South Africa) and the Arctic. ${ }^{5}$ Furthermore, it is reported that endosulfan is abundant in food (fish, fruits, vegetables and dairy products). ${ }^{6}$

The global ban on the manufacture and use of endosulfan was negotiated under the Stockholm Convention and will take effect in mid-2012, with the possibility of a few exemptions for further five years. Some countries are against its banning. For example, India expressed concern that farming and the country's food security will be adversely affected. At present, endosulfan is listed as a POP in the Convention on Long-range Transboundary Air Pollutants and as a Persistent Toxic Substance by the International POPs Elimination Network. ${ }^{7}$

It is of importance to measure exposure to toxic substances (including organic pollutants) in pregnant women, because this gives an indication of prenatal exposures. During pregnancy, the deposition of persistent organic chemicals can be affected by physiological changes (increased renal perfusion and volume of distribution, and increased serum lipids), and as most of these substances are lipophilic, an increase of serum lipids can cause their redistribution to blood compartments. ${ }^{8}$ The pesticides can be transferred from the mother to the foetus across the placenta during pregnancy and to the newborn baby through breastfeeding. ${ }^{9,10}$

A number of studies have investigated not only the association between gestational age and POPs exposure, but also the exposure during breastfeeding. ${ }^{11,12}$ To date, inconclusive results indicate that delays in growth and neurodevelopment of the foetus and the breastfed infant can be related to late gestational exposures, meaning that exposure during pregnancy is more toxic than breastfeeding., ${ }^{2,13}$

South Africa is one of the largest users of pesticides in the African continent. Since 1994, the South African government in an effort to address imbalances of the political past has implemented a policy of land redistribution where $46 \%$ of the agricultural land was redistributed to women, increasing the number of female headed households. This has led to a change in women's roles in agriculture, such as pesticide mixing and application, which was previously done mainly by males. ${ }^{14}$ In traditional households, women also frequently work on farms of their husband or other owners. In addition, women who own the farms may be under pressure to return to work early after giving birth, so as to supervise and participate in the farming activities. ${ }^{15}$

Furthermore, progress in social and economic development in the rural areas of South Africa resulted in a change from mainly subsistence to a mixture of subsistence, cash crop and commercial farming. The need for pesticide use has therefore increased.
A number of South African studies show a presence of various pesticides and their metabolites in occupationally exposed farm workers. ${ }^{15-18}$ It has been shown that the use of lindane (which has been banned from agricultural use in South Africa since 2009) for head lice and scabies control resulted in this compound entering wastewater treatment plants which probably caused recycled water to be contaminated. ${ }^{19}$

Little is known about agricultural (both large and small scales) and household exposures to pesticides among rural communities in general, but particularly about exposures during pregnancy.

The aim of our study was to assess exposure to selected pesticides during pregnancy in women residing in three different sites along the Indian Ocean coast of South Africa. The study was performed by the South African Medical Research Council, National Institute for Air Research (NILU) and University of Tromsø, Norway, under bilateral research collaboration between South Africa and Norway.

\section{Materials and methods}

\section{Study sites}

KwaZulu Natal is a very suitable location to study exposure to pesticides used for agricultural activities within South Africa as this province has high amounts of rainfall throughout the year and large areas of arable land suitable for growing of sugar cane, vegetables and fruits. Choice of study sites was based on the proximity to the coast and included malaria endemic, intermittent malaria and non-malaria sites.

The study site 1 (malaria endemic - vicinity of Manguzi) is mainly suitable for livestock and subsistence farming, the study site 2 (non-malaria - vicinity of Port Shepstone) has sugarcane and commercial fruit farming, and the study site 3 (intermittent malaria - vicinity of Empangeni) has extensive commercial sugarcane, fruit and vegetable farms. Subsistence farming is common to all study sites (Fig. 1).

\section{Study population and data collection}

The study population consisted of pregnant women who were admitted for delivery to the local government hospitals. Ninetyone $(n=91)$, a hundred and one $(n=101)$ and forty-nine $(n=49)$ study participants were recruited from the 3 study sites, respectively $(n=241)$. The inclusion criteria were permanent residency in the area for at least 10 years. Volunteers who agreed to participate signed the informed consent forms and agreed to donate blood before delivery and allowed access to their postpartum records (delivery outcomes and eventual complications). Data on socioeconomic background, demographic factors, and diet and lifestyle measures were obtained by interview in the language of their choice applied by trained researchers and research assistants.

\section{Sampling procedure}

Samples of whole blood were taken from the mother before delivery with standard vacutainer equipment into EDTA tubes. The blood was centrifuged, plasma removed and frozen immediately at $-20{ }^{\circ} \mathrm{C}$. The samples were transported frozen to the National Institute for Air Research, Tromsø, Norway for 


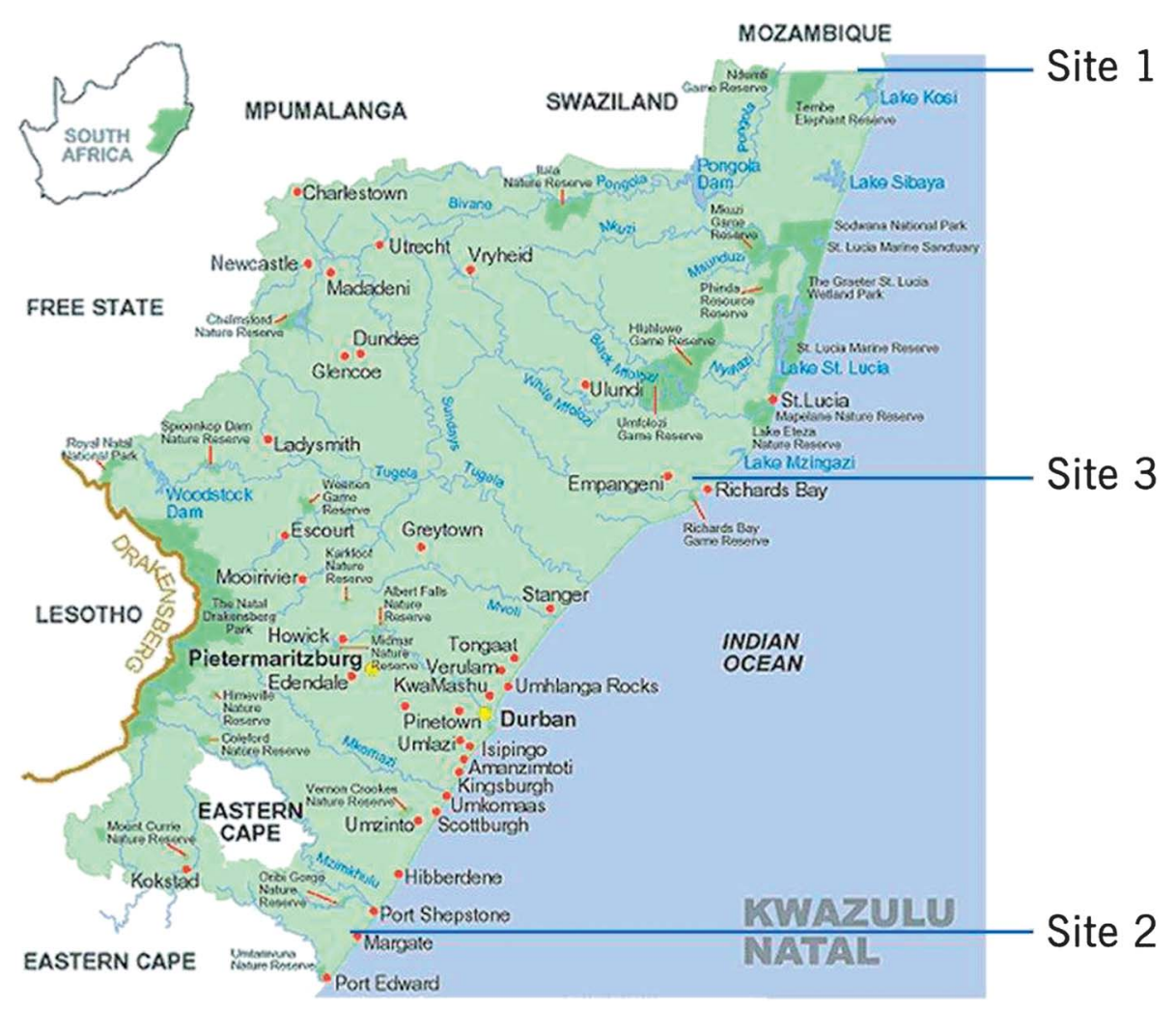

Fig. 1 Geographical positions of the study sites within KwaZulu Natal, South Africa.

analyses of $\alpha-, \beta-, \gamma-\mathrm{HCH}$, endosulfan 1, endosulfan 2, HCB and the pyrethroids: cis-permethrin, cyfluthrin, cypermethrin and deltamethrin. All standard procedures were applied during sample collection and analytical procedures to avoid any contamination.

\section{Laboratory analysis}

The analytical methodology follows previously described methods for the determination of organochlorine pesticides in plasma samples, namely, solid phase extraction (SPE), using a Rapidtrace Automated SPE workstation. ${ }^{20}$ Briefly, to the plasma samples $(2 \mathrm{ml})$, the internal standards (C13 labelled $\alpha$-, $\beta$-, $\gamma-\mathrm{HCH}, \mathrm{HCB}$, endosulfan 1 and endosulfan 2), formic acid $(2 \mathrm{ml})$ and water $(2 \mathrm{ml})$ were added, vortexed and left overnight in the refrigerator. The compounds were extracted on an Oasis ${ }^{\circledR}$ HLB extraction Cartridge $\left(3 \mathrm{~cm}^{3}, 540 \mathrm{mg}\right.$ : Waters Corp., Milford, MA, USA) using dichloromethane $(14 \mathrm{ml})$. The extracted samples were evaporated, resuspended in hexane and eluted through a column containing $1 \mathrm{~g}$ of deactivated silica. The samples were eluted with hexane-dichloromethane $(9 / 1 ; 6 \mathrm{ml})$ and dichloromethane $(6 \mathrm{ml})$, and concentrated and then a recovery standard (octachloronaphthalene) was added. The compounds were analysed on an Agilent 7890A gas chromatograph and a 5975C mass spectrometer (Agilent Technologies, Böblingengen, Germany). GC analysis was performed on a $30 \mathrm{~m}$ DB 5 column $(0.25 \mathrm{~mm}$ id and $0.25 \mu \mathrm{m}$ film thickness; $\mathrm{J} \& \mathrm{~W}$ Folsom, USA). An injection volume of $2 \mu \mathrm{l}$ was injected in splitless mode on the GC. The initial oven temperature was $70^{\circ} \mathrm{C}$ for $1 \mathrm{~min}$, thereafter ramped by $10^{\circ} \mathrm{C} \min ^{-1}$ to $310^{\circ} \mathrm{C}$ and kept for $5 \mathrm{~min}$. The quantitation was done using negative chemical ionization (NCI) in selected ion (SIM) mode. Methane was used as the reagent gas and helium was used as the carrier

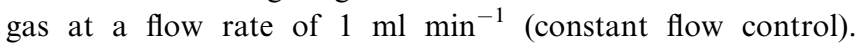
The transfer line and quadrupole temperatures were $200^{\circ} \mathrm{C}$ and $180{ }^{\circ} \mathrm{C}$, respectively.

The different compounds were identified based on their SIM masses and retention times.

Quality control and validation. For every 8 samples, a blank was analysed for laboratory contamination. The limit of detection (LOD) was calculated using three times the area of noise or if peaks were found in blanks, three times the area of the blank. Spiked bovine serum samples were analysed after every 12 samples and Standard Reference Material 1957 from the National Institute of Standards and Technology was analysed after every 24 samples. The percentage recovery for the organochlorines was $90-117 \%$ and $100-120 \%$ for the pyrethroids. The coefficient of variation was $12 \%$ for $\beta-\mathrm{HCH}$ and $20 \%$ for cyfluthrin in spiked bovine serum samples. Subjects with undetectable values were assigned detection limit of the corresponding biomarker divided by the square root of 2 , before correction for lipids to minimise the bias of removing them from the analysis completely. ${ }^{21}$

\section{Total lipid enzymatic method}

Lipids were determined enzymatically and the total lipids were calculated according to a formula as done by Sandanger et al. $^{22}$ 


\section{Statistical analysis}

All data analyses were performed using STATA package, version 11 for windows (STATA 11.1, 2009). Descriptive statistics were calculated to determine the characteristics of the sample: the Chi squared test and the Kruskal-Wallis test were performed to examine relationships, if any, to potential predictors of pesticide levels. A relationship was considered statistically significant if $p \leq 0.05$.

In order to decrease the variability and obtain distributions closer to normality, $\gamma$-HCH was log-transformed.

\section{Ethical consideration}

Unconditional ethical approval, indicating no changes to the protocol were required, for the study was obtained from the Human Research Ethics Committee (Medical) of the University of the Witwatersrand (Protocol: M040314). In addition, this study was approved by the Provincial Health Research Committee, KwaZulu-Natal Department of Health (Reference: HRKM001/08).

\section{Results}

\section{General characteristics of the participants}

The most common language spoken in all three sites was Zulu (100\%, 87\% and 98\%, respectively, for sites 1, 2 and 3). The majority of participants were African Blacks, excluding the 2\% that were of Asian origin in sites 2 and 3. Living in a rural area was most common in all three sites $(99 \%, 90 \%$ and $73 \%$ for sites 1,2 and 3 , respectively). A small percentage $(5 \%, 13 \%$, and $7 \%$ ) of subjects lived in an informal or shack instead of a house in the 3 sites, respectively. $4 \%, 16 \%$ and $11 \%$ of subjects were permanently employed at the three sites, respectively. The women from all sites reported an average family income of R4000. A total of 39\%, 33\% and $52 \%$ of mothers completed both secondary and tertiary education at the three sites, respectively. More than $50 \%$ of the women participating were having their first child in sites 1 and 2 , and $43 \%$ in site 3 . The mean age of the mothers at delivery was 24 years in sites 1 and 2, and 25 years in site 3, showing no significant differences and the mean weight at delivery was $71 \mathrm{~kg}, 76 \mathrm{~kg}$ and $74 \mathrm{~kg}$ in the three sites, respectively. None of the mothers reported smoking or drinking any alcohol during pregnancy. A large percentage of the mothers $(80 \%, 67 \%, 79 \%$, respectively, for sites 1,2 and 3 ) reported using pesticides in their home to control pests. Although, $87 \%, 43 \%$ and $72 \%$, respectively, for sites 1,2 and 3 of the mothers indicated that they grew their own food, only $74 \%$, $17 \%$ and $48 \%$ in sites 1,2 and 3 , respectively, of the women reported using pesticides in the garden. Majority of the women ate meat $(64 \%, 48 \%, 44 \%)$, fish $(47 \%, 37 \%, 21 \%)$, poultry $(52 \%, 45 \%$, $48 \%)$, butter and cheese $(36 \%, 25 \%, 37 \%)$ during the pregnancy at least once a week, compared to daily, at the three sites, respectively. In contrast, women reported a higher frequency of eating vegetables $(67 \%, 63 \%, 43 \%)$ and fruits $(29 \%, 62 \%, 61 \%)$ daily.

\section{Pesticide levels in maternal plasma}

Overall, plasma samples from 241 women at delivery age from 14 to 45 years in three regions of KwaZulu Natal were analysed for selected pesticides. For each study site, the geometric mean (GM), range and LOD value for each compound measured in maternal plasma (pg ml ${ }^{-1}$ ) and the percentage of detected compounds higher than LOD are presented in Table 1. Of the selected pesticides measured, only $\gamma-\mathrm{HCH}$ had concentrations above the LOD in more than $99 \%$ of the samples. Endosulfan 1 was detected in more than $95 \%$ of samples in sites 1 and 3 , but only $73 \%$ of the samples in site 2 were above the LOD. In contrast, endosulfan 2 was detected in $95 \%$ of the samples in site 3 , but only $34 \%$ and $24 \%$ were above the LOD in sites 1 and 2 , respectively. The geometric mean of $\gamma-\mathrm{HCH}$ and endosulfan 1 and 2 was highest in site 3 and the differences between the sites were statistically significant $(p<0.05) . \alpha-\mathrm{HCH}$ was detected in $14 \%, 4 \%$ and $30 \%$ of the samples in the three sites, respectively. HCB showed no results above the LOD, whereas the pyrethroids and $\beta-\mathrm{HCH}$ showed results between 0 and $28 \%$ above the LOD, with no significant differences between the three sites.

Lipid corrected ( $\mathrm{ng} \mathrm{g}^{-1}$ lipids) results of selected pesticides in maternal plasma are shown in Table 2. Site 3 had the highest GM levels for $\alpha-\mathrm{HCH}, \gamma-\mathrm{HCH}$, endosulfan 1 and 2. The GM for $\alpha-\mathrm{HCH}$ was low at $3 \mathrm{ng} \mathrm{g}^{-1}$ lipids in site 3 and $2 \mathrm{ng} \mathrm{g}^{-1}$ lipids for sites 1 and 2. The $\gamma$-HCH GM level in site 3 of $956 \mathrm{ng} \mathrm{g}^{-1}$ lipids was approximately seven times higher than those found in sites 1 and 2. The GM of endosulfan 1 in site 3 was approximately six and fourteen times higher than sites 1 and 2, respectively. Endosulfan 2 GM levels were also much higher in site 3. Endosulfan 1 and 2 and $\gamma$-HCH GM levels were statistically significant between the three sites.

\section{Correlations of selected pesticides}

To evaluate the uses of and exposure to the different pesticides, correlations were examined. In site 1 , endosulfan 1 correlated strongly and positively with endosulfan $2(r=0.83)$ and mildly correlated with $\alpha-\mathrm{HCH}(r=0.49)$ and $\gamma-\mathrm{HCH}(r=0.57)$. In site 2 , endosulfan 2 correlated very strongly and positively with endosulfan 1 and $\alpha-\mathrm{HCH}(r>0.7)$, and less strongly with $\gamma-\mathrm{HCH}$ $(r=0.64)$. Correlations in site 3 were also positive and strong between $\gamma$-HCH and endosulfan 1 and endosulfan $2(r>0.7)$. An expected strong correlation was also found between $\alpha$ - and $\gamma$-HCH $(r=0.69)$.

Fig. $2 \mathrm{a}-\mathrm{c}$ show the scatter plots between total endosulfan and $\gamma-\mathrm{HCH}$ in the three study sites, respectively. The outliers above $2000 \mathrm{ng} \mathrm{g}^{-1}$ lipids in site 3 were removed to indicate the differences in exposure of the three sites. Sites 1 and 2 have many values clustered between 0 and $500 \mathrm{ng} \mathrm{g}^{-1}$ lipids, whereas in site 3 concentrations of $\gamma-\mathrm{HCH}$ only begin above $400 \mathrm{ng} \mathrm{g}^{-1}$ lipids. In addition, site 3 has two distinct exposure groups, with one group looking similar to that of sites 1 and 2 and the other a definite high exposed endosulfan- $\gamma-\mathrm{HCH}$ group.

\section{Relationship of $\gamma-\mathrm{HCH}$ and endosulfan with various predictive variables}

The number of compounds with adequate numbers of samples above the limit of detection determined which pesticides were analysed further. A cut-off of $70 \%$ of levels above the LOD was chosen. Thus, only $\gamma-\mathrm{HCH}$ and total endosulfan were analysed. The number of subjects and GM concentrations ( $\mathrm{ng} \mathrm{g}^{-1}$ lipids) of 
Table 1 Pesticide concentrations $\left(\mathrm{pg} \mathrm{m}^{-1}\right)$ in maternal plasma at delivery by the study site

\begin{tabular}{|c|c|c|c|c|c|c|c|}
\hline & & Site $1, n=91$ & Site $2, n=101$ & Site $3, n=49$ & $\mathrm{LOD}^{b}$ & Overall $n^{d}$ detected > LOD & $p$-Value \\
\hline \multirow[t]{4}{*}{$\alpha-\mathrm{HCH}$} & $\mathrm{GM}^{a}$ & 15 & 14 & 19 & \multirow[t]{4}{*}{18} & \multirow[t]{4}{*}{40} & \multirow[t]{4}{*}{$\mathrm{ns}^{c}$} \\
\hline & Median & 13 & 13 & 13 & & & \\
\hline & Range & $13-164$ & $13-52$ & $13-47$ & & & \\
\hline & $\%$ Detected $>\mathrm{LOD}^{b}$ & 14 & 4 & 30 & & & \\
\hline \multirow[t]{4}{*}{$\mathrm{HCB}$} & GM & 64 & 64 & 64 & \multirow[t]{4}{*}{90} & \multirow[t]{4}{*}{0} & \multirow[t]{4}{*}{ ns } \\
\hline & Median & 64 & 64 & 64 & & & \\
\hline & Range & 64 & 64 & 64 & & & \\
\hline & $\%$ Detected $>$ LOD & 0 & 0 & 0 & & & \\
\hline \multirow[t]{4}{*}{$\beta-\mathrm{HCH}$} & GM & 65 & 64 & 65 & \multirow[t]{4}{*}{90} & \multirow[t]{4}{*}{3} & \multirow[t]{4}{*}{$\mathrm{ns}$} \\
\hline & Median & 64 & 64 & 64 & & & \\
\hline & Range & $64-336$ & 64 & $64-114$ & & & \\
\hline & $\%$ Detected $>$ LOD & 1 & 0 & 2 & & & \\
\hline \multirow[t]{4}{*}{$\gamma-\mathrm{HCH}$} & GM & 775 & 816 & 6140 & \multirow[t]{4}{*}{20} & \multirow[t]{4}{*}{252} & \multirow[t]{4}{*}{$<0.05$} \\
\hline & Median & 717 & 680 & 6097 & & & \\
\hline & Range & $70-58256$ & $14-10623$ & $2775-11405$ & & & \\
\hline & $\%$ Detected $>$ LOD & 100 & 99 & 100 & & & \\
\hline \multirow[t]{4}{*}{ Endosulfan 1} & GM & 153 & 66 & 837 & \multirow[t]{4}{*}{24} & \multirow[t]{4}{*}{230} & \multirow[t]{4}{*}{$<0.05$} \\
\hline & Median & 106 & 51 & 702 & & & \\
\hline & Range & $17-18589$ & $17-5100$ & $158-7384$ & & & \\
\hline & $\%$ Detected > LOD & 97 & 73 & 100 & & & \\
\hline \multirow[t]{4}{*}{ Endosulfan 2} & GM & 28 & 21 & 119 & \multirow[t]{4}{*}{20} & \multirow{4}{*}{119} & \multirow[t]{4}{*}{$<0.05$} \\
\hline & Median & 14 & 14 & 71 & & & \\
\hline & Range & $14-3353$ & $14-1608$ & $14-2420$ & & & \\
\hline & $\%$ Detected > LOD & 34 & 24 & 95 & & & \\
\hline \multirow[t]{4}{*}{$c$-Per methrin } & GM & 7 & 7 & 7 & 8 & 28 & ns \\
\hline & Median & 6 & 6 & 6 & & & \\
\hline & Range & $6-75$ & $6-86$ & $6-50$ & & & \\
\hline & $\%$ Detected $>$ LOD & 11 & 11 & 12 & & & \\
\hline Cyfluthrin & GM & 4 & 4 & 3 & 4 & 33 & ns \\
\hline & Median & 3 & 3 & 3 & & & \\
\hline & Range & $3-44$ & $3-78$ & $3-29$ & & & \\
\hline & $\%$ Detected $>$ LOD & 22 & 13 & 11 & & & \\
\hline Cyper methrin & GM & 3 & 3 & 3 & 4 & 23 & ns \\
\hline & Median & 3 & 3 & 3 & & & \\
\hline & Range & $3-18$ & $3-11$ & $3-16$ & & & \\
\hline & $\%$ Detected > LOD & 14 & 9 & 7 & & & \\
\hline Delta methrin & GM & 6 & 6 & 6 & 8 & 12 & ns \\
\hline & Median & 6 & 6 & 6 & & & \\
\hline & Range & $6-55$ & $6-102$ & $6-48$ & & & \\
\hline & $\%$ Detected > LOD & 4 & 6 & 5 & & & \\
\hline
\end{tabular}

plasma of $\gamma-\mathrm{HCH}$ with selective predictive variables that could have an effect are shown in Table 3. Drinking river or borehole water significantly increased $\gamma$-HCH levels in mothers in site 1 compared to drinking municipality water which was received via the tap which could be outside or inside the house. In site 1, $\gamma$-HCH levels were significantly increased in women who reported using pesticides in the garden and growing their own food. In contrast, growing their own food reduced the levels of $\gamma$ $\mathrm{HCH}$ in site $3(p=0.0662)$. Using pesticides in the home significantly decreased the levels of $\gamma-\mathrm{HCH}$ in site $3(p=0.0145)$. However, the small number of mothers that said no to using pesticides in home could likely influence the significance. For total endosulfan the same variables were examined, however, only the number of children was found to be a significant predictor of higher levels in site 2 . The dietary intake during pregnancy had no influence on the $\gamma-\mathrm{HCH}$ and endosulfan levels.

\section{Discussion}

Most of the published research in South Africa has estimated human exposure to a limited number of pesticides, generally
DDT and metabolites, or occasionally, pyrethroids, organophosphates and endosulfan. ${ }^{16,23}$ Our previously published data on a pilot study measuring pesticide exposure in delivering women throughout South Africa indicated $\gamma-\mathrm{HCH}$ to be the dominant pesticide in six of the seven chosen sites and DDT was the most dominant in the two malaria endemic sites. ${ }^{24}$ In the current study, we have quantified ten selected pesticides in South African delivering women residing along Indian Ocean in three sites in the province of KwaZulu Natal.

Of all the pesticides quantified, $\gamma-\mathrm{HCH}$ and endosulfan were dominant in all the three study sites. $\gamma-\mathrm{HCH}$ and endosulfan levels were found to be significantly higher in site 3 when compared to levels in sites 1 and 2. The $\gamma-\mathrm{HCH}$ levels in site 3 were approximately seven times higher than in sites 1 and 2 . The elevated levels and the relatively short half-life of $\gamma-\mathrm{HCH}$ ( 8 days), and endosulfan indicate recent and on-going exposure possibly from the use of shampoos containing $\gamma-\mathrm{HCH}$ or food and environmental exposure in all three sites. ${ }^{25,26}$ Study site 3 (vicinity of Empangeni) is surrounded by mixed farming compared to the other two sites; these high levels could come from the pesticide usage at the farms, with women being active 
Table 2 Lipid corrected ( $\mathrm{ng} \mathrm{g}^{-1}$ lipids) results of pesticides in maternal plasma at the three sites

\begin{tabular}{|c|c|c|c|c|}
\hline Compounds & Statistics & $\begin{array}{l}\text { Site 1, } \\
n=91\end{array}$ & $\begin{array}{l}\text { Site 2, } \\
n=101\end{array}$ & $\begin{array}{l}\text { Site 3, } \\
n=49\end{array}$ \\
\hline \multirow[t]{4}{*}{$\alpha-\mathrm{HCH}$} & $\mathrm{GM}^{a}$ & 2 & 2 & 3 \\
\hline & Median & 2 & 2 & 2 \\
\hline & Range & $2-30$ & $1-10$ & $1-15$ \\
\hline & $\mathrm{IQR}^{b}$ & $2-3$ & $2-2$ & $2-5$ \\
\hline \multirow[t]{4}{*}{$\gamma-\mathrm{HCH}$} & GM & 127 & 127 & 956 \\
\hline & Median & 122 & 115 & 902 \\
\hline & Range & $9-10494$ & $2-2132$ & $416-3829$ \\
\hline & IQR & $61-198$ & $55-278$ & $743-1274$ \\
\hline \multirow[t]{4}{*}{ Endosulfan 1} & GM & 25 & 10 & 141 \\
\hline & Median & 19 & 8 & 102 \\
\hline & Range & $3-3348$ & $2-542$ & $24-1142$ \\
\hline & IQR & $10-48$ & $4-18$ & $66-286$ \\
\hline \multirow[t]{4}{*}{ Endosulfan 2} & GM & 5 & 3 & 21 \\
\hline & Median & 3 & 2 & 13 \\
\hline & Range & $2-604$ & $1-171$ & $2-374$ \\
\hline & IQR & $2-7$ & $2-4$ & $8-49$ \\
\hline
\end{tabular}

farm workers. In addition to the high levels of $\gamma-\mathrm{HCH}$ and endosulfan found in this study, the mothers may be exposed to DDT as Bouwman et al. have reported elevated levels of DDT in the region. ${ }^{27}$

Our study found that in South Africa, exposure occurs mainly from lindane (lindane is known as $\gamma-\mathrm{HCH}$ since it is made up of at least $99 \%$ of $\gamma-\mathrm{HCH}$ ), and not technical $\mathrm{HCH}$ (which can include varying proportions of $\alpha-, \beta-, \delta$ - and $\varepsilon-\mathrm{HCH}$ ), due to high levels of $\gamma-\mathrm{HCH}$ in all three sites and very low levels of $\alpha$ - and $\beta$-HCH. ${ }^{28}$ In addition, the levels of $\gamma-\mathrm{HCH}$ indicate recent use since $\gamma-\mathrm{HCH}$ is degraded more rapidly than $\alpha$ - and $\beta-\mathrm{HCH}$. Thus, if exposure was historic we would expect to find higher levels of $\alpha$ - and $\beta-\mathrm{HCH}$ in our samples compared to $\gamma-\mathrm{HCH} .{ }^{28}$

$\gamma-\mathrm{HCH}$ was produced until the early 1980s in South Africa and banned in 2009, and even though the environmental and agricultural use of certain pesticides may be prohibited, residues are frequently found in environmental samples. Residual studies in soil and sedimentation done in South Africa before 1997 showed $\gamma-\mathrm{HCH}$ to be the most prevalent organochlorine pesticide (with more than $80 \%$ contribution to total $\mathrm{HCH}$ levels) followed by endosulfan. ${ }^{29}$ These soil results compare well with our study findings, as $\gamma-\mathrm{HCH}$ was the most prevalent in maternal plasma samples followed by endosulfan.

$\beta-\mathrm{HCH}$ is known to be the most persistent $\mathrm{HCH}$ isomer and many studies found $\beta-\mathrm{HCH}$ and $\mathrm{HCB}$ to be the dominant pesticides, excluding DDT. ${ }^{30-33}$ However, very low levels of these compounds were found in this study, suggesting no long-term or on-going exposure to these compounds. It also shows worldwide variations in pesticide levels.

Although the GMs were similar in all sites for $\alpha-\mathrm{HCH}$, the frequency of detectable levels varied, with site 3 being the highest $(30 \%)$ and only 14 and $4 \%$ in sites 1 and 2 , respectively. This is possibly due to $\alpha-\mathrm{HCH}$ being a by-product in the production of $\gamma-\mathrm{HCH}$ and the highest levels of $\gamma-\mathrm{HCH}$ were found in site $3{ }^{34}$

The GM plasma concentration of $\gamma-\mathrm{HCH}$ measured in site 3 was $6140 \mathrm{pg} \mathrm{ml}^{-1}$, which is similar to levels reported in maternal plasma samples from India, with a mean of $5230 \mathrm{pg} \mathrm{ml}^{-1} \cdot{ }^{35}$ India is a well-known user of pesticides, indicating that site 3 has high
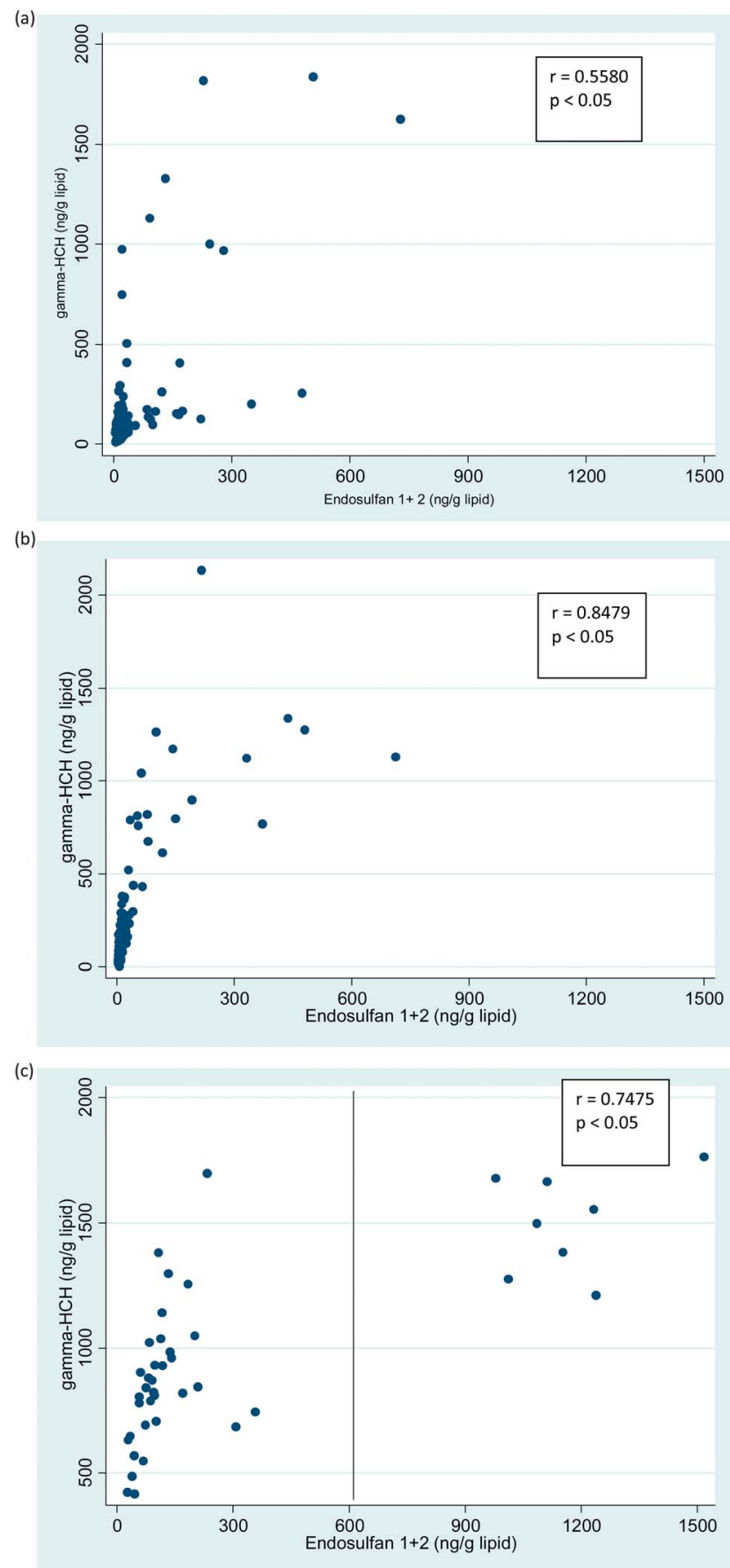

Fig. 2 (a) Scatter plot of $\gamma-\mathrm{HCH}$ and total endosulfan in site 1, (b) scatter plot of $\gamma-\mathrm{HCH}$ and total endosulfan in site 2 and (c) scatter plot of $\gamma-\mathrm{HCH}$ and total endosulfan in site 3 showing two distinct exposure groups.

pesticide use. The levels of $\gamma-\mathrm{HCH}$ at all three sites were higher than those reported from Poland, where Jaraczewska et al. found $\gamma$-HCH levels below the limit of quantitation ( $4 \mathrm{ng} \mathrm{g}^{-1}$ lipids) in all maternal serum samples; and in Brazil where delivering women had a median level of $3 \mathrm{pg} \mathrm{ml}^{-1}$ in blood samples. ${ }^{30,32}$

Endosulfan is among the most frequent contaminants found in food, soil and water. ${ }^{36}$ In the environment, endosulfan 1 and endosulfan 2 persist for 800 and 60 days, respectively. ${ }^{37}$ The long 
Table 3 Relationship with selective variables and $\gamma-\mathrm{HCH}$ (ng g ${ }^{-1}$ lipids) ${ }^{a}$

\begin{tabular}{|c|c|c|c|c|c|c|c|}
\hline \multicolumn{8}{|l|}{$\gamma-\mathrm{HCH}$} \\
\hline \multirow[b]{2}{*}{ Predictors } & & \multicolumn{2}{|l|}{ Site 1} & \multicolumn{2}{|l|}{ Site 2} & \multicolumn{2}{|l|}{ Site 3} \\
\hline & & $n^{b}(\mathrm{GM})^{c}$ & $p$-Value & $n(\mathrm{GM})$ & $p$-Value & $n(\mathrm{GM})$ & $p$-Value \\
\hline \multirow[t]{4}{*}{ Age } & $14-19$ & $26(121)$ & 0.1564 & $27(149)$ & 0.2465 & $8(1132)$ & 0.1324 \\
\hline & $20-29$ & $37(135)$ & & $65(130)$ & & $25(948)$ & \\
\hline & $30-39$ & $13(67)$ & & $16(79)$ & & $11(767)$ & \\
\hline & $\geq 40$ & $4(256)$ & & 0 & & $2(905)$ & \\
\hline \multirow[t]{2}{*}{ Type of residence } & Urban & $1(25)$ & 0.1871 & $10(117)$ & 0.8113 & 12(936) & 0.9629 \\
\hline & Rural & $79(123)$ & & $98(128)$ & & $31(930)$ & \\
\hline \multirow[t]{4}{*}{ No of children } & 0 & $44(148)$ & 0.3909 & $56(113)$ & 0.6125 & $20(1021)$ & 0.4839 \\
\hline & 1 & $16(88)$ & & $33(147)$ & & $10(839)$ & \\
\hline & 2 & $8(95)$ & & $8(153)$ & & $7(854)$ & \\
\hline & $>3$ & $11(99)$ & & $8(88)$ & & $8(907)$ & \\
\hline \multirow[t]{2}{*}{ Source of drinking water } & Tap & $53(87)$ & 0.0040 & $100(127)$ & 0.9105 & $37(975)$ & 0.4246 \\
\hline & Other & $27(226)$ & & $8(138)$ & & $9(754)$ & \\
\hline \multirow[t]{2}{*}{ Pesticides used in the home } & Yes & $63(108)$ & 0.5556 & $72(123)$ & 0.9132 & $37(920)$ & 0.0145 \\
\hline & No & $17(176)$ & & $36(137)$ & & $9(958)$ & \\
\hline \multirow[t]{2}{*}{ Grow own food } & Yes & $68(145)$ & 0.0005 & $48(131)$ & 0.8913 & $33(872)$ & 0.0662 \\
\hline & No & $12(42)$ & & $59(127)$ & & $13(1084)$ & \\
\hline \multirow[t]{2}{*}{ Pesticides used in the garden } & Yes & $58(146)$ & 0.0161 & $16(118)$ & 0.6798 & $19(885)$ & 0.4472 \\
\hline & No & $22(72)$ & & $78(136)$ & & $22(967)$ & \\
\hline \multirow[t]{2}{*}{ Breastfeeding } & Never & $41(137)$ & 0.2495 & $47(139)$ & 0.9129 & $16(959)$ & 0.1144 \\
\hline & Cumulative breastfed & $26(89)$ & & $24(136)$ & & $13(825)$ & \\
\hline
\end{tabular}

persistence of endosulfan 1 in the environment could explain the higher levels of endosulfan 1 found in our study. Site 3 participants had the highest combined endosulfan GM levels and the highest detection rate of $\geq 95 \%$. The frequency of detection of endosulfan 1 was higher in site 1 compared to site 2 . Although subjects in sites 1 and 2 were exposed to endosulfan, ongoing exposure to endosulfan is evident in site 3 . In all three sites, endosulfan 1 correlated strongly and positively with endosulfan 2, indicating a similar source of exposure. Strong positive correlations were also found between $\gamma-\mathrm{HCH}$ and endosulfan, suggesting similar sources of exposure.

Although the GM level of $837 \mathrm{pg} \mathrm{ml}^{-1}$ for endosulfan 1 in site 3 was the highest in this study, the concentration was still lower than those reported from India, where endosulfan is still used. ${ }^{38}$ Pathak et al. have reported mean levels of total endosulfan in maternal blood of $3700 \mathrm{pg} \mathrm{ml}^{-1} \cdot{ }^{38} \mathrm{In}$ Spain, Torres et al. reported very high levels of endosulfan 2 of $76380 \mathrm{pg} \mathrm{ml}^{-1}$ in delivering mothers, and in Brazil, Sarcinelli et al. reported endosulfan levels in mothers of $108 \mathrm{pg} \mathrm{ml}^{-1}$, lower than our results. ${ }^{39,40}$ A study by Dalvie et al. found low concentrations of endosulfan in rural and other drinking water sources in Western Cape, South Africa, indicating widespread prevalence of this pesticide in the country and possible environmental contamination. ${ }^{41}$ More attention should be given to endosulfan, because of the frequency of their residues in human tissue and their important estrogenic activity. ${ }^{\mathbf{2}}$

The other pesticides measured in this study were HCB and the pyrethroid pesticides: cis-permethrin, cyfluthrin, cypermethrin, and deltamethrin. HCB was found to be below detectable levels in all samples. The pyrethroids were detected in less than $23 \%$ of the samples. The low levels of pyrethroids in all three sites can be explained by the fact that pyrethroids have a very short half-life, and therefore, to get a good measure of exposure, sampling has to be done soon after exposure has taken place. The frequency of cyfluthrin and cypermethrin detection was higher in site 1 compared to the other two sites, whereas $c$-permethrin and deltamethrin were similar in all sites. A study by Bouwman et al. performed in the same province detected the presence of pyrethroids in breast milk samples, ${ }^{23}$ suggesting that exposure is common. In addition, residential insecticide use is known to be widespread in South Africa, and all commercial household sprays contain one or more pyrethroids. ${ }^{43}$ In the USA, following the restriction of organophosphorus insecticides, the use of pyrethroids, especially permethrin and PBO (piperonyl butoxide) increased. ${ }^{44}$ Another study reported the presence of cypermethrin $(1.7 \%)$ and cyfluthrin $(0.8 \%)$ in meconium samples, but none were found in blood samples of delivering mothers from an agricultural site in the Philippines. ${ }^{45}$

Questionnaire information was also collected in this study on possible modifiers of plasma pesticide levels. Very few studies have examined the association between determinants and plasma levels of $\gamma-\mathrm{HCH}$. In pregnant women, variation in pesticide levels may be explained by a potential dilution effect as a consequence of weight gain, different sources of exposure, age, physical activity, diet and toxicokinetics. ${ }^{46,47}$ In another study, where $\gamma$-HCH levels were quantified, the $\gamma-\mathrm{HCH}$ levels were too low to allow for robust analysis of associations. ${ }^{48}$

The results from our study clearly show that breastfeeding a child and the number of children had no impact on plasma $\gamma$-HCH levels. However, in adipose tissue samples Cerrillo et al. found significantly $(p<0.05)$ higher levels in subjects from Spain that had breastfed their children compared to those that did not, and as the number of children increased $\gamma-\mathrm{HCH}$ levels increased. ${ }^{49}$

The predictors of $\gamma$ - $\mathrm{HCH}$ levels that were statistically significant in our study, including growing their own food and using pesticides in the garden/home, were not found to be significantly 
associated in the study by Cerrillo et al. ${ }^{49}$ Both studies, however, found that age and type of residence did not play a role in $\gamma-\mathrm{HCH}$ levels. Bradman et al. also found a lack of association between serum levels of $\gamma-\mathrm{HCH}$ in pregnant Latina women from California and exposure risk factors, including breastfeeding and agricultural work. ${ }^{50}$ The lack of association between breastfeeding and $\gamma-\mathrm{HCH}$ is likely due to the short half-life of the compound.

Cerrillo et al. also found significantly higher levels of endosulfan 1 in adipose tissue of subjects who lived in an urban area and participants who had more children. ${ }^{49}$ Our study did not find any significant predictors for high endosulfan levels.

Regional differences in the use of $\gamma-\mathrm{HCH}$ and endosulfan in the KwaZulu Natal province of South Africa may explain the distinct frequencies of exposure to these chemicals found in the different sites. However, study site 3 clearly shows a group of participants highly exposed both to $\gamma-\mathrm{HCH}$ and endosulfan. The scatter plot from site 3 in Fig. 2 shows two distinct groups when correlating endosulfan and $\gamma-\mathrm{HCH}$ plasma levels. After separating the two groups, none of the predictors collected in this study showed a significant difference between the two groups. This may be due to the questionnaire not having the questions that could identify the source of exposure in the site. The questionnaire did not address the type of pesticides used by the subjects, a limitation of the study. Further research is therefore required to identify the source of this high exposure.

Our study was cross-sectional and relied on pregnant women to remember and truthfully answer interview questions. Every effort was taken to get reliable information such as conducting interviews in the women's home language, but there still may have been information bias due to cultural misunderstanding or poor recall. In site 3 , where the highest pesticide levels were found, the fewest participants were recruited, and thus reduced the power of the analyses. Sampling bias maybe possible due to the unequal number of subjects at the three sites, and only subjects that delivered at the government hospitals were included in the study and not those that had home births or delivered at a private hospital.

After the data were collected for this study in 2008, South Africa banned the use of lindane in $2009,{ }^{51}$ thus a follow up study is needed to determine if the ban has had any significant effect on the lowering of $\gamma-\mathrm{HCH}$ in the study population.

\section{Conclusion}

This study presents one of the first analyses of selected pesticide concentrations in plasma of delivering women in South Africa. We found $\gamma-\mathrm{HCH}$ and endosulfan to be the predominant pesticides in maternal plasma samples. The levels of both $\gamma-\mathrm{HCH}$ and endosulfan were significantly elevated in the area with the most commercial farming, with women as farm workers, compared to the other two areas sampled in KwaZulu Natal. The results indicate that pregnant rural women living along the coast of KwaZulu Natal, South Africa, are exposed to a variety of pesticides. These findings will influence future recommendations for decreasing pesticide levels and avoiding their negative health effects on not only pregnant woman and the health of susceptible but also the general population. Pesticides can be stored in the mother's body and transferred prenatally to the developing foetus during pregnancy or postnatally from breast milk to the nursing infant. Therefore, the results of this study of high levels of exposure to selected pesticides in women are of great concern.

\section{Acknowledgements}

The authors deeply thank the Research Council of Norway and the National Research Foundation, South Africa (Grant 64528), the Arctic Monitoring and Assessment Programme (AMAP), the Royal Norwegian Ministry for Foreign Affairs and the SA Medical Research Council for financial support. We also thank all the participants, relevant health departments, maternity sections and staff of the hospitals. Special thanks to Prof. Piet Baker for overviewing of data input and Miriam Mogotsi for her expert research assistance in data and sample collection from the Medical Research Council. Thanks to Linda Hanssen and Charlotta Rylander from the National Institute for Air Research (NILU) for their invaluable analytical expertise.

\section{References}

1 A. Polder, T. N. Savinova, A. Tkachev, K. B. Loken, J. O. Odland and J. U. Skaare, Sci. Total Environ., 2010, 408, 5352-5361.

2 S. Patandin, P. C. Dagnelie, P. G. Mulder, E. Op de Coul, J. E. van der Veen, N. Weisglas-Kuperus and P. J. Sauer, Environ. Health Perspect., 1999, 107, 45-51.

3 J. Vijgen, P. C. Abhilash, Y. F. Li, R. Lal, M. Forter, J. Torres, N. Singh, M. Yunus, C. Tian, A. Schaffer and R. Weber, Environ. Sci. Pollut. Res., 2011, 18, 152-162.

4 M. Aqiel Dalvie, A. Africa and L. London, Sci. Total Environ., 2006, 361, 8-17.

5 UNEP, Global Monitoring Plan for Persistent Organic Pollutants First Regional Monitoring Draft Report Africa Region, 2009, http:// chm.pops.int/Portals/0/Repository/GMP/UNEP-POPS-GMP-RMRAFR.English.PDF, 13 February 2012.

6 Z. Liu, H. Zhang, M. Tao, S. Yang, L. Wang, Y. Liu, D. Ma and Z. He, Arch. Environ. Contam. Toxicol., 2010, 59, 444- 453.

7 IPEN, Endosulfan Fact Sheet, 2008, http://www.ipen.org/ipenweb/ documents/poprc $\% 20$ documents/endosulfan $\% 20$ fact $\% 20$ sheet $\%$ 20pan\%20urope.pdf, accessed 13 February 2012.

8 D. L. Phillips, J. L. Pirkle, V. W. Burse, J. T. Bernert, Jr, L. O. Henderson and L. L. Needham, Arch. Environ. Contam. Toxicol., 1989, 18, 495-500.

9 H. A. Anderson and M. S. Wolff, J. Exposure Anal. Environ. Epidemiol., 2000, 10, 755-760.

10 A. Nair, R. Mandapati, P. Dureja and M. K. Pillai, Bull. Environ. Contam. Toxicol., 1996, 56, 58-64.

11 M. P. Longnecker, M. A. Klebanoff, B. C. Gladen and H. W. Berendes, Arch. Environ. Health, 1999, 54, 110-114.

12 J. L. Jacobson and S. W. Jacobson, N. Engl. J. Med., 1996, 335, 783789.

13 M. K. Siddiqui, S. Srivastava, S. P. Srivastava, P. K. Mehrotra, N. Mathur and I. Tandon, Int. Arch. Occup. Environ. Health, 2003, 76, $75-80$.

14 S. Naidoo, L. London, A. Burdorf, R. N. Naidoo and H. Kromhout, Int. J. Occup. Environ. Health, 2008, 14, 218-224.

15 S. Naidoo, L. London, A. Burdorf, R. Naidoo and H. Kromhout, Scand. J. Work, Environ. Health, 2011, 37, 227-236.

16 M. A. Dalvie, A. Africa, A. Solomons, L. London, D. Brouwer and H. Kromhout, J. Environ. Sci. Health, Part B, 2009, 44, 271-277.

17 G. A. Heeren, J. Tyler and A. Mandeya, Environ. Health, 2003, 2, 11.

18 L. London, V. Nell, M. L. Thompson and J. F. Myers, S. Afr. Med. J., 1998, 88, 1096-1101.

19 UASA, UASA Water Security Seminar, Responding to Realities II, 2010, http://www.h2o4life.co.za/pdf/21-05-2010_media_release.pdf, accessed 13 February 2012.

20 T. M. Sandanger, M. Sinotte, P. Dumas, M. Marchand, C. D. Sandau, D. Pereg, S. Berube, J. Brisson and P. Ayotte, Environ. Health Perspect., 2007, 115, 1429-1434. 
21 R. W. Hornung and L. D. Reed, Appl. Occup. Environ. Hyg., 1990, 5, 46-51.

22 T. M. Sandanger, M. Brustad, E. Lund and I. C. Burkow, J. Environ. Monit., 2003, 5, 160-165.

23 H. Bouwman, B. Sereda and H. M. Meinhardt, Environ. Pollut., 2006, 144, 902-917.

24 H. B. Rollin, T. M. Sandanger, L. Hansen, K. Channa and J. O. Odland, Sci. Total Environ., 2009, 408, 146-152.

25 L. Drummond, E. M. Gillanders and H. K. Wilson, Br. J. Ind. Med., 1988, 45, 493-497.

26 F. J. Arrebola, J. L. Martinez Vidal and A. Fernandez-Gutierrez, Toxicol. Lett., 1999, 107, 15-20.

27 H. Bouwman, P. J. Becker and C. H. Schutte, Bull. W. H. O., 1994, 72, 921-930.

28 K. Mishra, R. C. Sharma and S. Kumar, Ecotoxicol. Environ. Saf., 2012, 76, 215-225.

29 B. L. P. Quinn, J. de Vos, M. Fernandes-Whaley, C. Roos, H. Bouwman, H. Kylin, R. Pieters and J. van den Berg, Pesticides in the modern world - Pesticides use and management, ed. $\mathrm{M}$. Stoytcheva, InTech, 2011.

30 C. V. Rudge, T. Sandanger, H. B. Rollin, I. M. Calderon, G. Volpato, J. L. Silva, G. Duarte, C. M. Neto, N. Sass, M. U. Nakamura, J. O. Odland and M. V. Rudge, Environ. Int., 2011, 162-169.

31 L. L. Cao, C. H. Yan, X. D. Yu, Y. Tian, L. Zhao, J. X. Liu and X. M. Shen, Sci. Total Environ., 2011, 409, 2997-3002.

32 K. Jaraczewska, J. Lulek, A. Covaci, S. Voorspoels, A. KalubaSkotarczak, K. Drews and P. Schepens, Sci. Total Environ., 2006, 372, 20-31.

33 H. Shen, K. M. Main, H. E. Virtanen, I. N. Damggard, A. M. Haavisto, M. Kaleva, K. A. Boisen, I. M. Schmidt, M. Chellakooty, N. E. Skakkebaek, J. Toppari and K. W. Schramm, Chemosphere, 2007, 67, S256-S262.

34 A. M. Ingelido, A. Abballe, V. Marra, S. Valentini, A. Ferro, M. G. Porpora, P. G. Barbieri and E. De Felip, Ann. Ist. Super. Sanita, 2009, 45, 401-408.

35 R. Pathak, R. S. Ahmed, A. K. Tripathi, K. Guleria, C. S. Sharma, S. D. Makhijani and B. D. Banerjee, Clin. Biochem., 2009, 42, 746749 .

36 IPEN, Endosulfan Meets the POPs Screening Criteria, 2008, www.ipen.org, accessed 15 September 2011.
37 R. A. Doong, C. Y. Lee and Y. C. Sun, J. AOAC Int., 1999, 82, 677 682.

38 R. Pathak, S. G. Suke, R. S. Ahmed, A. K. Tripathi, K. Guleria, C. S. Sharma, S. D. Makhijani, M. Mishra and B. D. Banerjee, Bull. Environ. Contam. Toxicol., 2008, 81, 216-219.

39 P. N. Sarcinelli, A. C. Pereira, S. A. Mesquita, J. J. Oliveira-Silva, A. Meyer, M. A. Menezes, S. R. Alves, R. C. Mattos, J. C. Moreira and M. Wolff, Environ. Res., 2003, 91, 143-150.

40 M. Jimenez Torres, C. Campoy Folgoso, F. Canabate Reche, A. Rivas Velasco, I. Cerrillo Garcia, M. Mariscal Arcas and F. Olea-Serrano, Sci. Total Environ., 2006, 372, 32-38.

41 M. A. Dalvie, E. Cairncross, A. Solomon and L. London, Environ. Health, 2003, $2,1$.

42 A. M. Soto, C. Sonnenschein, K. L. Chung, M. F. Fernandez, N. Olea and F. O. Serrano, Environ. Health Perspect., 1995, 103(suppl. 7), $113-122$.

43 S. Tolosana, H. A. Rother and L. London, S. Afr. Med. J., 2009, 99, $180-184$.

44 M. K. Williams, A. Rundle, D. Holmes, M. Reyes, L. A. Hoepner, D. B. Barr, D. E. Camann, F. P. Perera and R. M. Whyatt, Environ. Health Perspect., 2008, 116, 1681-1688.

45 E. M. Ostrea, Jr, D. M. Bielawski, N. C. Posecion, Jr, M. Corrion, E. Villanueva-Uy, R. C. Bernardo, Y. Jin, J. J. Janisse and J. W. Ager, Environ. Res., 2009, 109, 116-122.

46 M. Kotlyar and S. W. Carson, Int. J. Clin. Pharmacol. Ther., 1999, 37, $8-19$.

47 M. S. Wolff, E. Deych, F. Ojo and G. S. Berkowitz, Environ. Res., 2005, 97, 170-177.

48 A. Glynn, M. Aune, P. O. Darnerud, S. Cnattingius, R. Bjerselius, W. Becker and S. Lignell, Environ. Health, 2007, 6, 2.

49 I. Cerrillo, M. F. Olea-Serrano, J. Ibarluzea, J. Exposito, P. Torne, J. Laguna, V. Pedraza and N. Olea, Chemosphere, 2006, 62, $1917-$ 1924.

50 A. S. Bradman, J. M. Schwartz, L. Fenster, D. B. Barr, N. T. Holland and B. Eskenazi, J. Exposure Sci. Environ. Epidemiol., 2007, 17, 388 399.

51 Nedlac, An Investigation into the Extent of Manufacture, Use, Import and Export of New Chemicals Listed in Terms of the Stockholm and Rotterdam Conventions, 2010, www.nedlac.org.za/media/22316, accessed 13 February 2012. 